\title{
Endometriosis umbilical primaria. Reporte de dos casos
}

\section{Primary umbilical endometriosis. Two case reports}

\author{
Alba Táboas-Álvarez ${ }^{1 *}$, Ana López-Carrasco', Juan J. Velacoracho-Pérez¹, Shirin Zarbakhsh-Etemadi², \\ Laura Yébenes-Gregorio ${ }^{3}$, David Hardisson-Hernaez ${ }^{3}$ y Alicia Hernández-Gutiérrez ${ }^{1}$ \\ ${ }^{1}$ Departamento de Endometriosis, Servicio de Ginecología y Obstetricia; ${ }^{2}$ Servicio de Cirugía Plástica; ${ }^{3}$ Servicio de Anatomía Patológica. Hospital \\ Universitario La Paz, Madrid, España
}

\section{Resumen}

Introducción: La endometriosis es una patología benigna, dependiente de estrógenos, en la que el tejido que normalmente crece dentro del útero aparece fuera de este. Su localización habitual es en la pelvis, pero en ocasiones puede aparecer en otras áreas, como es el caso de la endometriosis umbilical. Objetivo: Familiarizar al ginecólogo con esta patología y entregar una serie de herramientas para diagnosticar, tratar y seguir a las pacientes que la presentan. Casos clínicos: Se presentan dos casos clínicos de endometriosis umbilical primaria diagnosticados en el Hospital La Paz, en Madrid (España), entre los años 2018 y 2019. Las pacientes, de 30 y 34 años, consultaron por dolor o sangrado umbilical durante la menstruación. Ninguna tenía antecedentes de patología ginecológica ni cirugía abdominal previa. Tras una exhaustiva exploración física y una ecografía de alta resolución, se decidió extirpar la lesión con la colaboración del servicio de cirugía plástica. En ambos casos, el estudio anatomopatológico confirmó que se trataba de tejido endometriósico. Las dos pacientes presentaron una buena evolución posquirúrgica, sin recidivas hasta la fecha. Conclusiones: La endometriosis umbilical primaria es una patología infrecuente, pero es necesario incluirla en el diagnóstico diferencial de una mujer con un nódulo umbilical. Siempre deben realizarse una exploración física exhaustiva y una ecografía ginecológica, para descartar posibles patologías concomitantes. El tratamiento de elección es la extirpación quirúrgica de la lesión y el diagnóstico final se establece con el estudio anatomopatológico.

Palabras clave: Endometriosis umbilical. Endometriosis primaria. Sangrado umbilical. Nódulo umbilical.

\section{Abstract}

Introduction: Endometriosis is an estrogen-dependent benign pathology in which endometrial tissue develops outside the uterus. It's most frequent location is the pelvis, although it can appear in other areas such as the umbilicum. Objective: To familiarize the gynecologist with this pathology and provide a series of tools to diagnose, treat and provide continued care to these patients. Case reports: Retrospective study of two clinical cases of primary umbilical endometriosis diagnosed at La Paz University Hospital, in Madrid (Spain), between 2018 and 2019. Both patients (30 and 34 years old respectively) presented with pain and/or bleeding around the umbilical area during menstruation. Neither of them had any previous gynecologic conditions or abdominal surgeries. After exhaustive physical examination and a high-resolution ultrasound, lesions were surgically removed in collaboration with the plastic surgery department. In both cases, histology confirmed the presence of endometrial tissue. Both patients made a full recovery after surgery and haven't had a recurrence of said lesions. Conclusions: Primary umbilical endometriosis is an infrequent disease. However, it must be included in the differential diagnosis of umbilical nodes in women. Exhaustive physical examination and gynecologic ultrasound should always be

Fecha de recepción: 26-12-2020

Fecha de aceptación: 15-11-2021

E-mail: alba.taboas.alvarez@gmail.com

DOI: 10.24875/RECHOG.M21000037
Disponible en internet: 07-02-2022 Rev Chil Obstet Ginecol. 2021;86(6):538-544

www. rechog.com 0048-766X / @ 2021 Sociedad Chilena de Obstetricia y Ginecología. Publicado por Permanyer. Éste es un artículo open access bajo la licencia CC BY-NC-ND (https://creativecommons.org/licenses/by-nc-nd/4.0/). 
performed to rule out any other pathologies. Surgical removal of the nodes is the preferred treatment, and the final diagnosis is reached through histology.

Keywords: Umbilical endometriosis. Primary endometriosis. Umbilical bleeding. Umbilical node.

\section{Introducción}

En el presente artículo se describen dos casos de endometriosis umbilical primaria diagnosticados en el Hospital Universitario La Paz, de Madrid (España), junto con una revisión de la literatura científica disponible hasta el momento. El objetivo es evaluar las características clínicas y epidemiológicas de las pacientes con esta patología, así como afianzar las bases para su diagnóstico, tratamiento y seguimiento posterior.

La endometriosis es una enfermedad benigna, dependiente de los estrógenos, en la cual el tejido que normalmente crece en el interior del útero aparece fuera de este 1 . Afecta en torno al $5-10 \%$ de las mujeres en edad fértil. Sus síntomas habituales incluyen dolor abdominal, alteración del ritmo intestinal e infertilidad, lo que influye de manera muy negativa en la calidad de vida de las pacientes. La gravedad de los síntomas no siempre coincide con la extensión de la enfermedad; algunas pacientes presentan afectación de varios órganos abdominales con síntomas inespecíficos que pueden dificultar el diagnóstico².

La localización habitual de la endometriosis suele ser intrapélvica, pero también puede aparecer en otras áreas. Una de ellas es la pared abdominal, habitualmente secundaria a cirugías ginecológicas u obstétricas, afectando a las cicatrices resultantes de estas. Sin embargo, la aparición de endometriosis en la pared abdominal de manera primaria en pacientes sin antecedentes de cirugía abdominal ni patología ginecológica previa resulta mucho menos frecuente.

Entre los escasos reportes de endometriosis primaria, la afectación umbilical es la más habitual y representa el $0,5-1 \%$ de todos los casos de tejido endometrial ectópico ${ }^{3}$.

\section{Caso clínico 1}

Mujer de 34 años que consulta por la aparición de un nódulo doloroso en la mitad derecha del ombligo, de 1 mes de evolución. Nuligesta, sin hábitos tóxicos, sin enfermedades conocidas ni antecedentes quirúrgicos. La paciente refiere que en ocasiones el nódulo resulta doloroso, sin relacionarlo con el ciclo menstrual. Recibió previamente tratamiento con dienogest y etinilestradiol ( $2 \mathrm{mg} / 0,03 \mathrm{mg}$ ) durante 2 años con fines anticonceptivos.
En la exploración física se observaron dos excrecencias en la región paraumbilical derecha, de $1 \mathrm{~cm}$ de diámetro cada una, ambas con hipersensibilidad a la palpación. Los genitales externos, la vagina, el útero y los ovarios eran normales en la exploración y en la ecografía transvaginal, sin visualizar ni palpar nódulos endometriósicos. También se realizó una ecografía abdominal, en la que se observó, en el lugar donde se palpaban las dos excrecencias, un nódulo sólido a nivel del tejido celular subcutáneo, de $12 \times 8 \times 13 \mathrm{~mm}$, hipoecoico, de bordes mal delimitados y escasa vascularización en su interior (Fig. 1).

Dado que la clínica de la paciente, la exploración física y el estudio ecográfico eran compatibles con el diagnóstico de endometriosis umbilical primaria, se decidió realizar la extirpación quirúrgica de la lesión. La cirugía se llevó a cabo de manera conjunta entre el ginecólogo especialista en endometriosis y el servicio de cirugía plástica, con la intención de conseguir un buen resultado estético. Con respecto a la técnica quirúrgica, que se llevó a cabo bajo anestesia general, se realizó incisión perimetral a la lesión con bisturí frío a nivel de la piel, estableciendo un margen de piel sana adyacente a la lesión de aproximadamente $1 \mathrm{~cm}$. A continuación, disección del tejido celular subcutáneo incluyendo el nódulo con bisturí eléctrico y tijeras de disección hasta alcanzar el peritoneo, consiguiendo extirpar dicho nódulo con una mínima apertura del peritoneo y asegurando la resección total de la lesión en el plano profundo (Fig. 2). Seguidamente, revisión de la hemostasia y del posible defecto de la fascia, descartando la necesidad de colocar una malla abdominal, por lo que se procedió al cierre de la fascia con sutura reabsorbible. Por último, los cirujanos plásticos realizaron una reconstrucción en $\mathrm{V}$ del ombligo anclando los colgajos a la fascia y suturando la piel con puntos simples con sutura monofilamento reabsorbible de 3.0 (Fig. 3). La evolución posquirúrgica fue satisfactoria y la paciente abandonó el hospital 24 horas después de la intervención.

La biopsia de la pieza quirúrgica confirmó que se trataba de endometriosis. En el estudio anatomopatológico se visualizaron abundantes glándulas endometriósicas rodeadas de estroma endometrial. La epidermis no mostraba alteraciones (Figs. 4 y 5 ). 


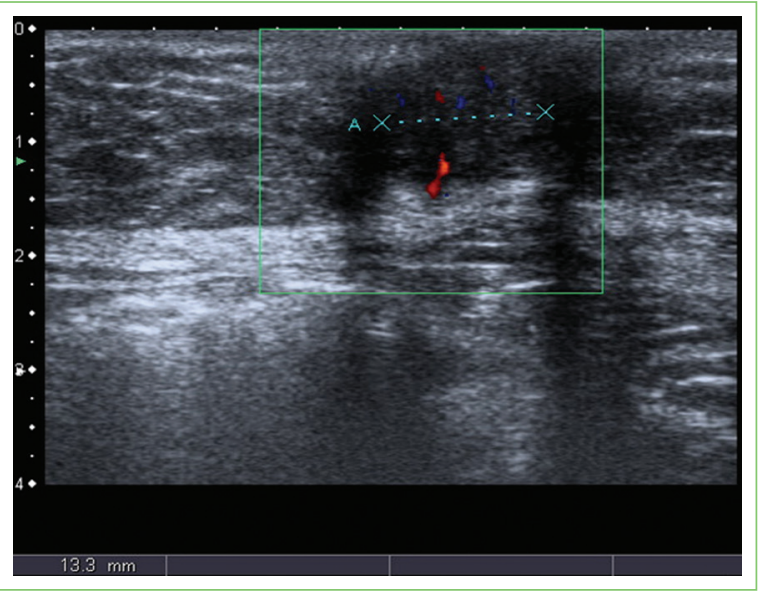

Figura 1. Ecografía abdominal del caso clínico 1.

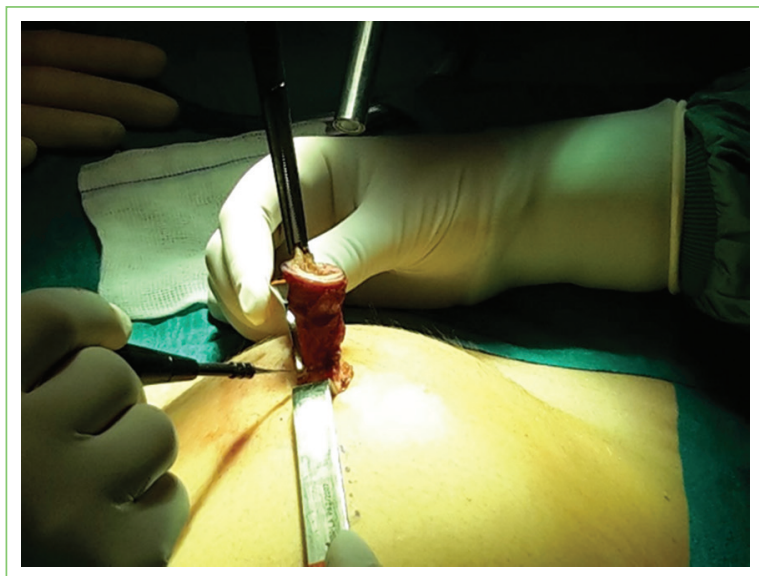

Figura 2. Extirpación quirúrgica del nódulo del caso clínico 1.

Tras la cirugía se restableció el tratamiento con anticonceptivos orales. Se pautó un seguimiento que incluyese exploración ginecológica y abdominal, y estudio ecográfico, cada 6 meses los primeros 2 años tras la cirugía, y posteriormente, en caso de no haber signos ni síntomas de riesgo, revisión anual. La paciente se encuentra asintomática hasta la fecha.

\section{Caso clínico 2}

Mujer de 30 años que consulta por un nódulo umbilical de varios años de evolución, que tras abandonar los anticonceptivos orales 3 meses atrás ha comenzado a sangrar coincidiendo con la menstruación. Así mismo, refiere clínica de larga evolución de dismenorrea y dispareunia.

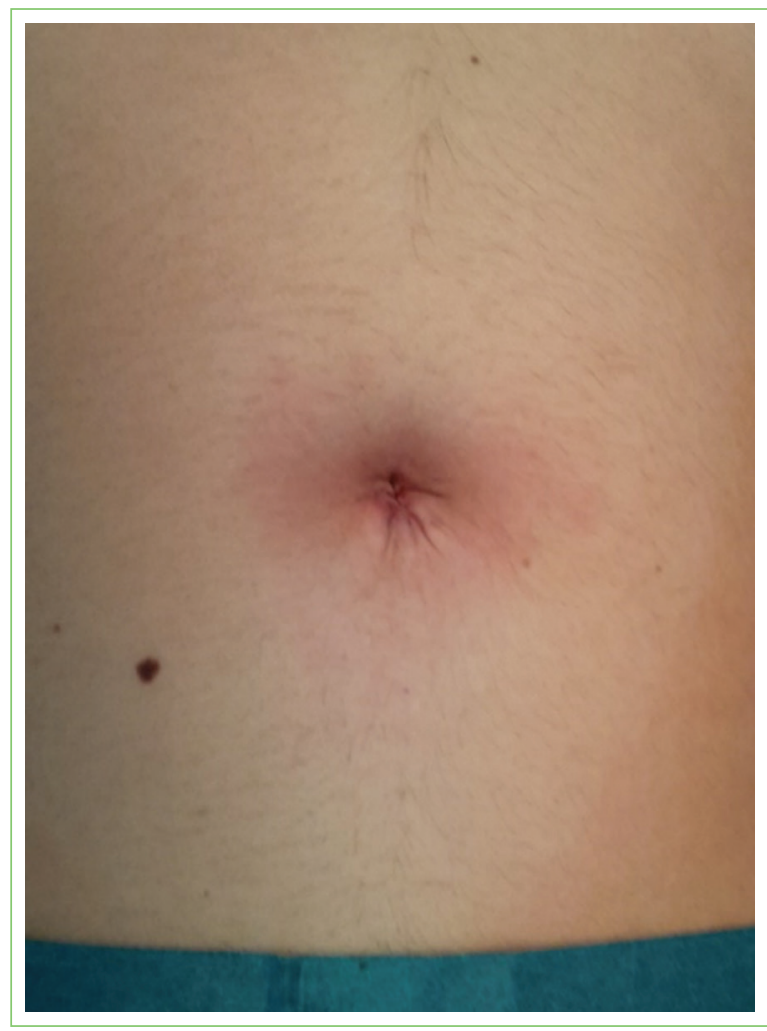

Figura 3. Reconstrucción en V del ombligo y cierre de la piel con puntos simples en el caso clínico 1.

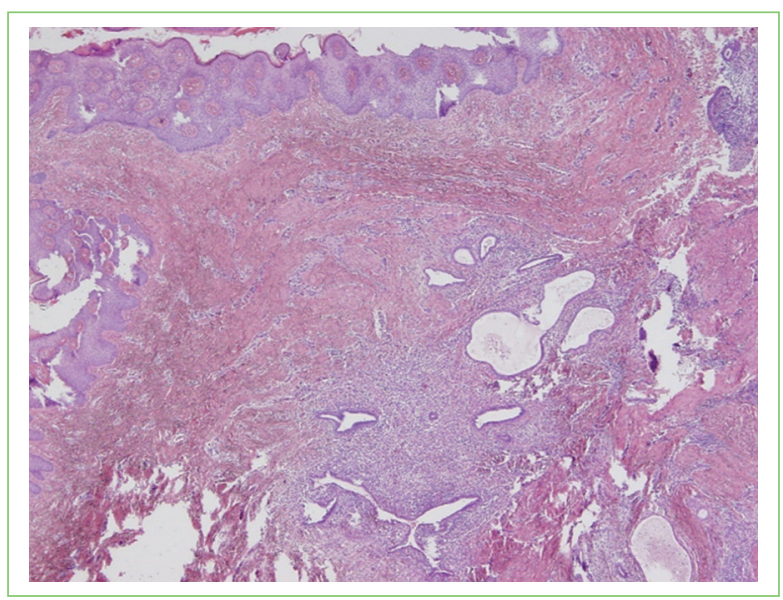

Figura 4. Estudio anatomopatológico de la pieza quirúrgica del caso clínico 1, en el que se visualizan abundantes glándulas endometriósicas rodeadas de estroma endometrial (hematoxilina-eosina 40x).

La paciente es fumadora de entre 5 y 10 cigarrillos al día. Como antecedentes obstétricos, ha tenido un aborto espontáneo del primer trimestre, y como antecedentes médicos, padece artritis reumatoide e hipotiroidismo. Se 


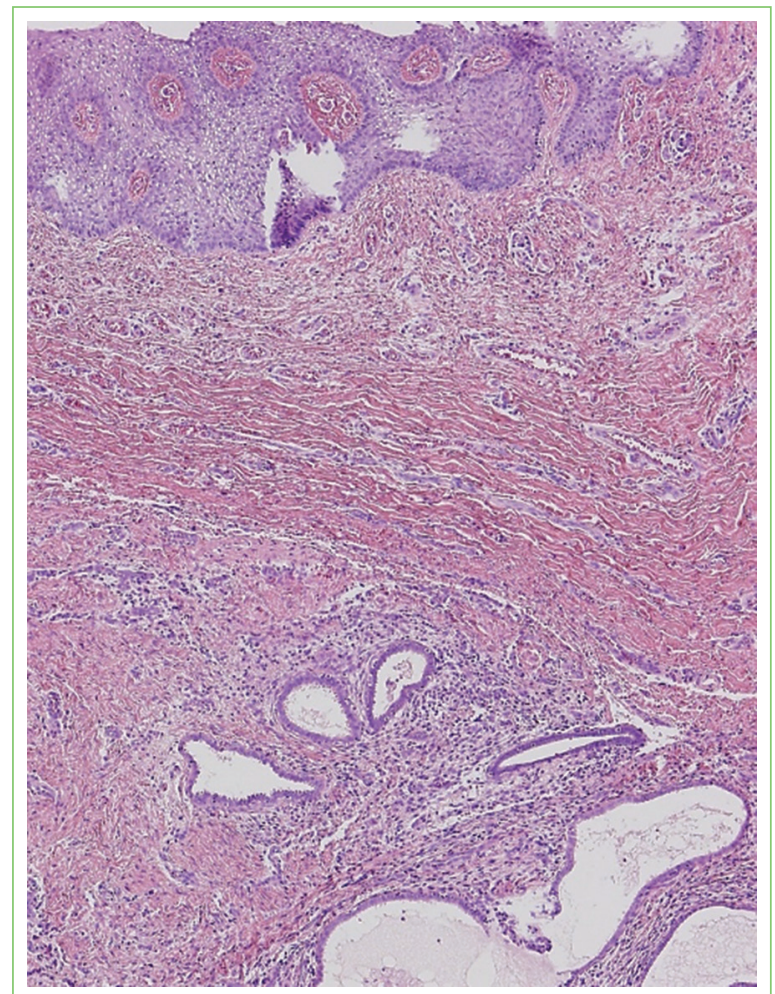

Figura 5. Estudio anatomopatológico de la pieza del caso clínico 1, en el que se aprecia el detalle de uno de los focos de endometriosis localizado en la dermis (hematoxilina-eosina 100x).

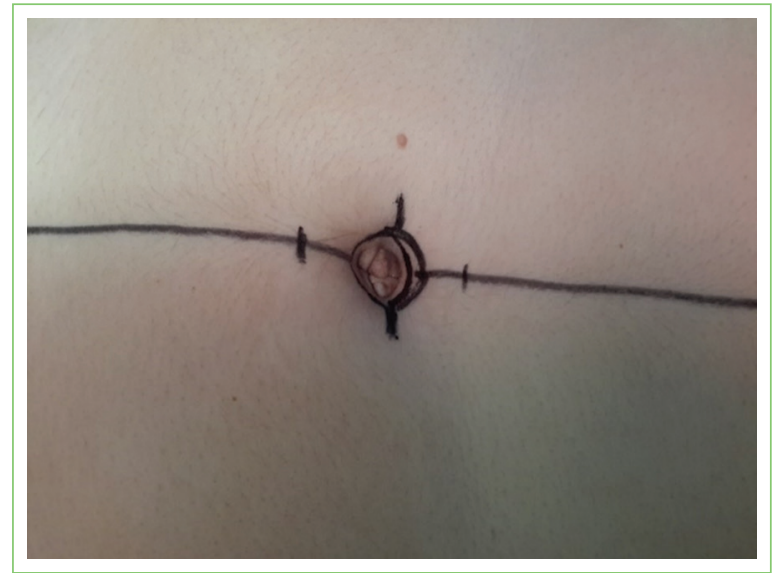

Figura 6. Exploración física del caso clínico 2.

le han practicado varias intervenciones quirúrgicas en la zona cervical, pero ninguna en el área abdominal.

En la exploración física se visualiza un nódulo umbilical de aproximadamente $1,5 \mathrm{~cm}$ de diámetro, ligeramente pigmentado y doloroso a la palpación (Fig. 6). El resto de la exploración física, tanto abdominal como

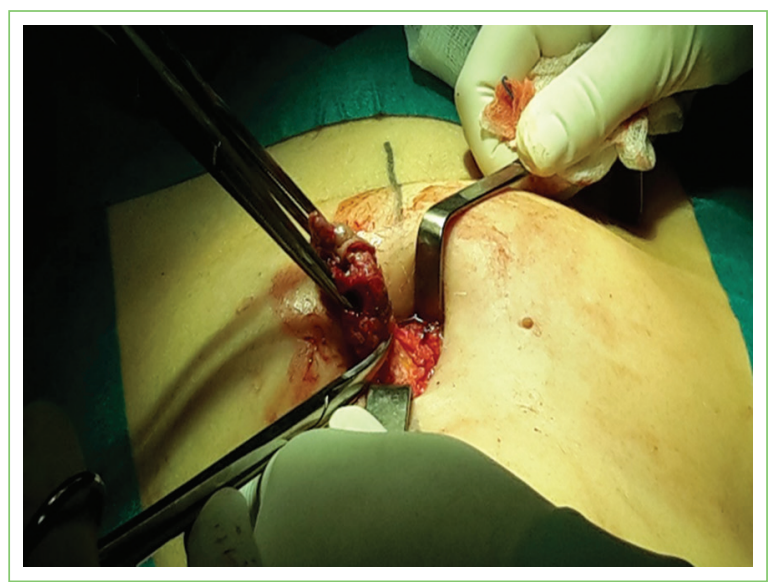

Figura 7. Extirpación quirúrgica del nódulo umbilical en el caso clínico 2.

ginecológica, fue estrictamente normal. El estudio ecográfico abdominal reveló un nódulo de $15 \mathrm{~mm}$ de diámetro, hipoecoico y de bordes irregulares en la pared abdominal. No hubo más hallazgos ecográficos pélvicos ni abdominales.

Dados los datos clínicos, físicos y ecográficos, se decidió extirpar la lesión umbilical. Al igual que en el caso anterior, se realizó la intervención de manera conjunta entre ginecólogos expertos en endometriosis y cirujanos plásticos (Figs. 7 y 8). La técnica quirúrgica, también realizada bajo anestesia general, fue muy similar a la descrita en el caso anterior, con incisión cutánea perimetral a la lesión y disección del tejido celular subcutáneo hasta alcanzar el peritoneo, pero al tratarse de una lesión que afectaba a la zona central del ombligo se realizó una amputación total de este. La principal diferencia en este caso radica en la reconstrucción del ombligo por parte de los cirujanos plásticos, que se realizó en bolsa de tabaco (Fig. 9).

No hubo incidencias en la recuperación posquirúrgica y el estudio anatomopatológico de la pieza confirmó el diagnóstico de endometriosis (Figs. 10 y 11).

La primera consulta de revisión fue al mes de la cirugía y luego se realizó otra consulta a los 3 meses; en ambas no hubo signos ni síntomas de recidiva, por lo que se decidió establecer las revisiones de manera anual por su ginecólogo habitual. Hasta la fecha, la paciente permanece asintomática.

\section{Discusión}

Según la localización de las lesiones, existen dos grandes grupos de endometriosis: pélvica y 


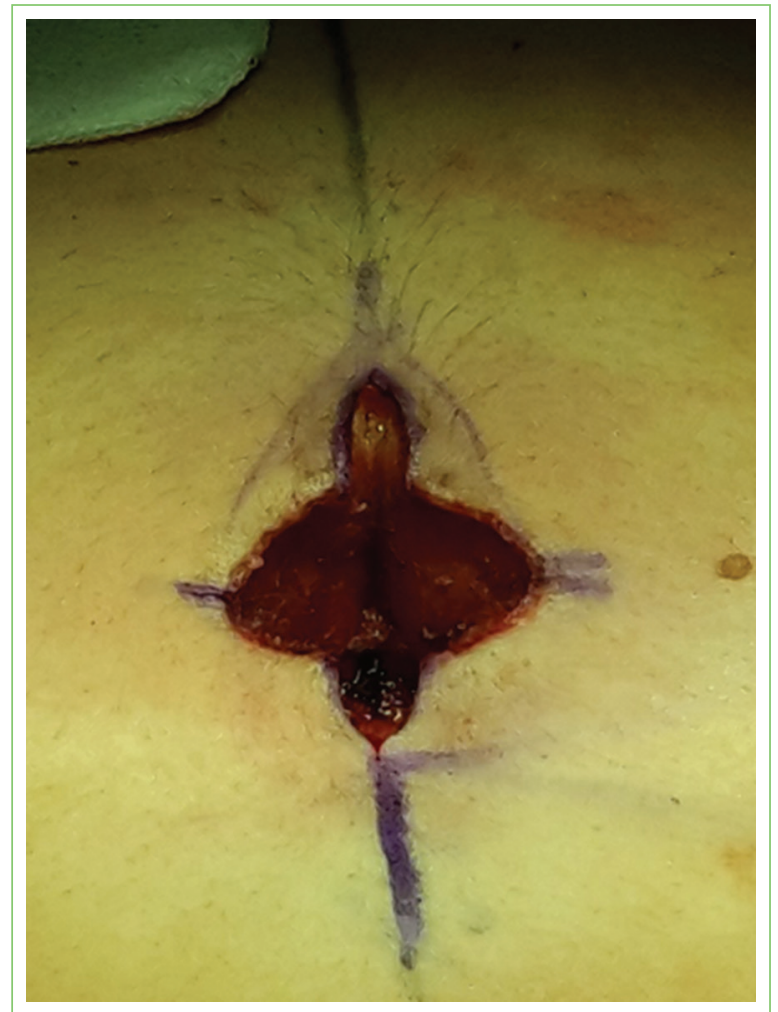

Figura 8. Aspecto del abdomen en el caso clínico 2 tras la extirpación del nódulo umbilical; se objetiva una amputación completa del ombligo.

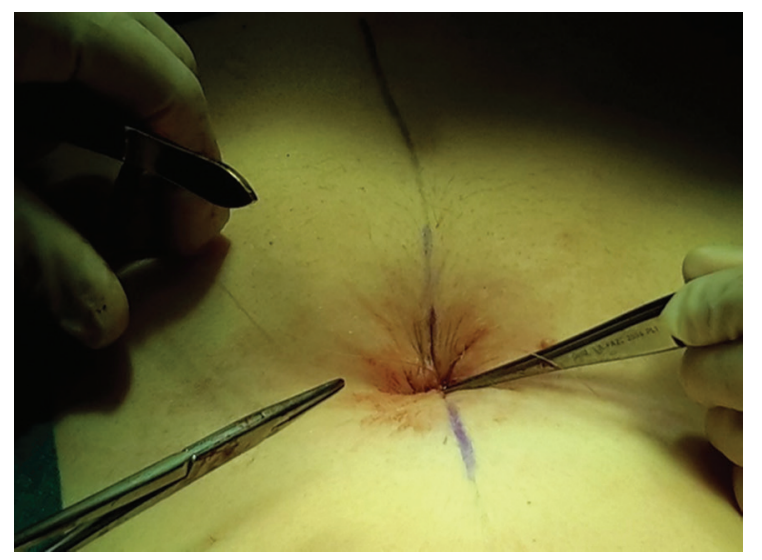

Figura 9. Reconstrucción del ombligo en el caso clínico 2, que se realizó con la técnica en bolsa de tabaco.

extrapélvica. El primer grupo es la ubicación típica de la endometriosis, representada por los ovarios y las trompas de Falopio (88\% de todos los casos) 4 . El grupo de endometriosis extrapélvica puede afectar a prácticamente todos los órganos (excepto el corazón y el

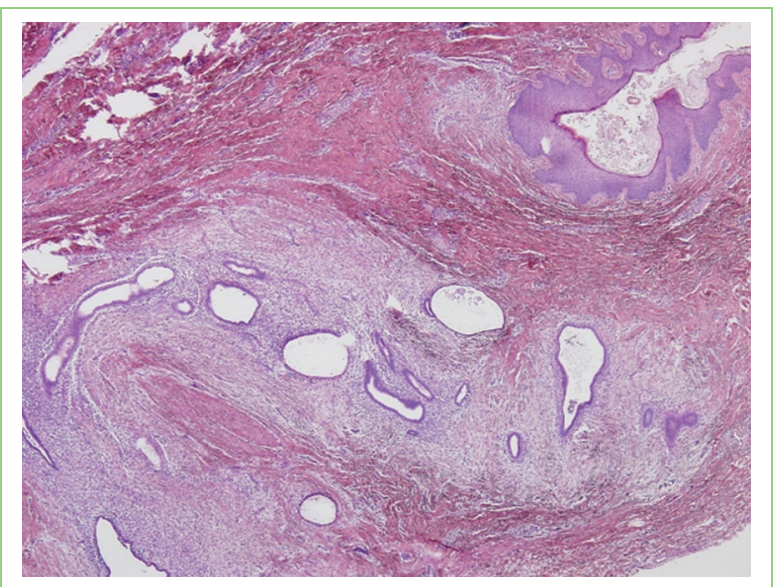

Figura 10. Estudio anatomopatológico de la pieza del caso clínico 2 en la que se visualizan glándulas endometriósicas rodeadas de estroma endometrial a nivel de la dermis superficial. Se puede apreciar que la epidermis (esquina superior derecha) no presenta ninguna alteración (hematoxilina-eosina 40x).

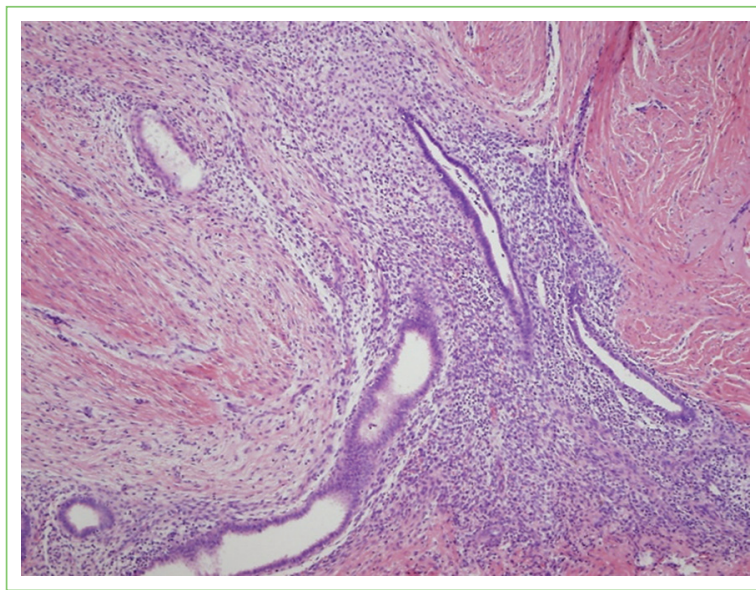

Figura 11. Muestra al detalle de uno de los focos de endometriosis (hematoxilina-eosina 100x).

bazo $)^{5}$. Su incidencia es muy baja, entre el $0,9 \%$ y el $1,5 \%$ de todos los casos de endometriosis, y la edad media de aparición es a los 34 años. La endometriosis umbilical cutánea es un proceso muy poco frecuente, pero es la localización más común de endometriosis extrapélvica $(3,2 \%$ al $40 \%)$. Puede confundirse con neoplasias primarias o metastásicas, granulomas, lipomas, abscesos y hernias. El riesgo de transformación maligna es mínimo ${ }^{6}$, aunque se han descrito algunos casos. Lauslahti ${ }^{7}$ informó por primera vez de un caso de adenocarcinoma de endometriosis umbilical en 1972, y Obata et al. ${ }^{8}$ describieron también el caso de 
una paciente con endometriosis adyacente a un carcinoma de células claras que se transformó en un carcinoma de endometriosis en la lesión umbilical. La endometriosis umbilical se clasifica a su vez como primaria, si aparece de manera espontánea, o como secundaria, en caso de que aparezca por la siembra iatrogénica de implantes endometriales tras procedimientos quirúrgicos. Este segundo grupo es mucho más frecuente ${ }^{9}$.

La etiología de la endometriosis todavía no se ha aclarado, pero cada vez existen más evidencias que sugieren que se trata de un complejo rasgo genético ${ }^{10}$. De acuerdo con la teoría más conocida, la teoría de la menstruación retrógrada de Sampson, durante la menstruación las células endometriales fluyen retrógradamente a través de las trompas de Falopio hasta llegar a la cavidad peritoneal. Otras fuentes posibles de células endometriales ectópicas pueden ser el mesotelio, células madre de la médula ósea, restos müllerianos, vestigios embrionarios, así como diseminación linfática o vascular, y metaplasia celómica ${ }^{11}$.

Con respecto a la endometriosis umbilical primaria, existen diversas teorías que intentan explicarla, aunque todavía no hay un consenso. Estas teorías se resumen esencialmente en dos: que las células son transportadas o que la endometriosis se desarrolla en el lugar donde aparece.

- Teoría del transporte intraperitoneal por menstruación retrógrada: Jenkins et al. ${ }^{12}$, en 1986, descubrieron que las mujeres con el útero en retroflexión tenían pocas posibilidades de presentar lesiones en el compartimento anterior de la pelvis, que serían más frecuente en aquellas con el útero en anteflexión forzada, ya que en las primeras el fluido regurgitado resbalaría hacia el compartimento posterior al no encontrar el útero como obstáculo ${ }^{12}$.

- Teoría de las metástasis benignas:

- Metástasis hemáticas: en una publicación de 1927, Sampson ${ }^{13}$ mostró por primera vez cómo fragmentos de tejido endometrial eran capaces de alcanzar la circulación venosa.

- Metástasis linfáticas: la presencia de tejido endometrial en los vasos linfáticos y los ganglios de mujeres con o sin endometriosis sugiere que la vía linfática contribuye a su diseminación ${ }^{14}$.

- Trasplante mecánico: existe relación entre el antecedente de cirugía abdominal y el incremento en la incidencia de lesiones endometriósicas extragenitales que afectan a la piel y los tejidos blandos ${ }^{15}$. Esto ocurre sobre todo en procedimientos que implican al útero y las trompas, en especial la cesárea, en relación a la cual se han publicado tasas de incidencia del $0,03 \%$ al $0,4 \%$. El mecanismo etiológico se ha relacionado con la siembra iatrogénica de células endometriales en las incisiones durante el procedimiento.

- Diseminación a través del sistema nervioso: Possover y Chiantera $^{16}$, en 2005, demostraron que en algunas pacientes se producía extensión de la enfermedad desde los ligamentos uterosacros a lo largo de los nervios esplácnicos, formulando una teoría: «la hipótesis neural». Más recientemente, Siquara de Sousa et al. ${ }^{17}$ propusieron «la propagación neural», teoría según la cual el sistema autonómico puede ser infiltrado directamente por la propagación directa de la endometriosis procedente de nódulos adenomióticos.

- Células progenitoras procedentes de la médula ósea: podrían originar endometriosis mediante su diferenciación en tejido endometrial ${ }^{18}$. Esta posibilidad apoyaría las teorías que defienden un origen no endometrial de la endometriosis.

- Teoría del desarrollo in situ: agrupa el concepto de metaplasia y el concepto de inducción, ambos anteriormente expuestos, y propone el surgimiento del tejido endometrial en el mismo punto donde se desarrolla la lesión a partir de tejidos locales, ya sea por su capacidad intrínseca de diferenciarse en tejido endometrial o porque ciertas sustancias impulsan su transformación. Clínicamente, la endometriosis umbilical afecta a mujeres en edad reproductiva y suele aparecer como un nódulo único, sólido y bien definido, de color rojo, azul o negro. En ocasiones se acompaña de dismenorrea, así como de sangrado o inflamación de la lesión durante la menstruación ${ }^{19}$, aunque algunos casos son totalmente asintomáticos ${ }^{20}$. El diagnóstico es clínico, debiendo sospecharlo siempre ante un nódulo umbilical en una mujer en edad fértil, pero habitualmente se retrasa debido a su baja prevalencia, por lo que pueden ser útiles ciertas pruebas de imagen, como la ecografía, la resonancia magnética o la tomografía computarizada. El tratamiento puede ser conservador, mediante vigilancia y, en función de los síntomas, añadir tratamiento con anticonceptivos, aunque se considera que la primera línea de tratamiento es habitualmente la cirugía ${ }^{21}$. La extirpación quirúrgica de la lesión suele ser sencilla, bajo anestesia general, y consiste en primer lugar en delimitar la incisión en la piel con bisturí frío, perimetral al nódulo, estableciendo un margen de piel sana adyacente a la lesión de aproximadamente $1 \mathrm{~cm}$. A continuación se lleva a cabo la disección del tejido celular subcutáneo con bisturí eléctrico y tijeras de 
disección, hasta alcanzar el peritoneo, para asegurar una resección total en el plano profundo. Se comprueban la hemostasia y posibles defectos de la fascia, valorando la necesidad de colocar una malla abdominal. Tras el cierre de la fascia con sutura reabsorbible, se procede a la reconstrucción del ombligo. A pesar de tratarse de una cirugía sencilla, es en este punto cuando la intervención de los cirujanos plásticos resulta más importante. Nuestra recomendación es realizar siempre una intervención conjunta entre ginecólogos especialistas en endometriosis, por la posible afectación intraabdominal que pudiera coexistir con el nódulo umbilical, y el servicio de cirugía plástica, para conseguir un mejor resultado estético, dado que han acudido a nuestra consulta varias pacientes que sufrieron una amputación del ombligo por intervenciones similares en otros centros, con las consecuencias estéticas que ello conlleva. Tras la cirugía, el diagnóstico se debe confirmar siempre mediante estudio anatomopatológico.

\section{Conclusiones}

La endometriosis umbilical primaria es una patología muy poco común, pero que debe tenerse en cuenta siempre como diagnóstico diferencial ante un nódulo umbilical en una mujer en edad fértil. Con respecto a la clínica, además del nódulo, las pacientes refieren habitualmente molestias en la zona y sangrado coincidente con la menstruación.

El diagnóstico es clínico, aunque en ocasiones pueden resultar útiles algunas técnicas de imagen para realizar un estudio más detallado de la lesión y una exploración ginecológica exhaustiva para descartar patología en otros lugares. El tratamiento es la extirpación quirúrgica de la lesión, que debe realizarse junto con un cirujano plástico para obtener los mejores resultados estéticos. Se recomienda seguimiento estrecho posterior al menos durante los primeros 2 años tras la cirugía para descartar posibles recidivas.

\section{Financiamiento}

Los autores declaran que para esta investigación no existen fuentes de financiamiento públicas o privadas en la realización del presente estudio.

\section{Conflicto de intereses}

Los autores declaran que para esta investigación no existe ningún conflicto de intereses relevante.

\section{Responsabilidades éticas}

Protección de personas y animales. Los autores declaran que para esta investigación no se han realizado experimentos en seres humanos ni en animales.

Confidencialidad de los datos. Los autores declaran que han seguido los protocolos de su centro de trabajo sobre la publicación de datos de pacientes.

Derecho a la privacidad y consentimiento informado. Los autores han obtenido el consentimiento informado de los pacientes y/o sujetos referidos en el artículo. Este documento obra en poder del autor de correspondencia.

\section{Bibliografía}

1. Chaichian S, Kabir A, Mehdizadehkashi A, Rahmani K, Moghimi M, Moazzami B. Comparing the efficacy of surgery and medical therapy for pain management in endometriosis: a systematic review and meta-analysis. Pain Physician. 2017;20:185-95.

2. Schomacker ML, Hansen KE, Ramlau-Hansen $\mathrm{CH}$, Forman A. Is endometriosis associated with irritable bowel syndrome? A cross-sectional study. Eur J Obstet Gynecol Reprod Biol. 2018;231:65-9.

3. Romera-Barba E, Castañer-Ramón-Llín J, Sánchez Pérez A, Navarro-García I, Rueda-Pérez JM, Cano Maldonado AJ, et al. Endometriosis umbilical primaria. A propósito de 6 casos. Revista Hispanoamericana de Hernia. 2014;2:105-10.

4. García-Santos EP, Muñoz-Atienza V, Sánchez-García S, Puerto-Puerto A, Ruescas-García FJ, Manzanares-Campillo MC, et al. Endometriosis de localización extraovárica. Nuestra casuística en 10 años. Prog Obstet Ginecol. 2014;57:117-20.

5. Guidice LC, Kao LC. Endometriosis. Lancet. 2004;364:1789-99.

6. Calagna G, Perino A, Chianetta D, Vinti D, Triolo MM, Rimi C, et al. Primary umbilical endometrioma: analyzing the pathogenesis of endometriosis from an unusual localization. Taiwan J Obstet Gynecol. 2015:54:306-12

7. Lauslahti K. Malignant external endometriosis. A case of adenocarcinoma of umbilical endometriosis. Acta Pathol Microbiol Scand Suppl. 1972;233:98-102.

8. Obata K, Ikoma N, Oomura G, Inoue Y. Clear cell adenocarcinoma arising from umbilical endometriosis. J Obstet Gynaecol Res. 2013;39:455-61.

9. Al-Khalili AA, Billick R. Umbilical endometriosis. Sultan Qaboos Univ Med J. 2017:17:e371-2.

10. Brown J, Crawford TJ, Datta S, Prentice A. Oral contraceptives for pain associated with endometriosis. Cochrane Database Syst Rev. 2018;(5):CD001019.

11. Schenken RS. Endometriosis: pathogenesis, clinical features, and diagnosis. UpToDate; 2021. Disponible en: https://www.uptodate.com/contents/endometriosis-pathogenesis-clinical-features-and-diagnosis

12. Jenkins S, Olive DL, Haney AF. Endometriosis: pathogenetic implications of the anatomic distribution. Obstet Gynecol. 1986;67:335-8.

13. Sampson JA. Metastatic or embolic endometriosis, due to the menstrual dissemination of endometrial tissue into the venous circulation. Am J Pathol. 1927:3:93-110.

14. Jerman LF, Hey-Cunningham AJ. The role of the lymphatic system in endometriosis: a comprehensive review of the literature. Biol Reprod. 2015:92:64.

15. Rani PR, Soundararaghavan S, Rajaram P. Endometriosis in abdominal scars - review of 27 cases. Int J Gynaecol Obstet. 1991;36:215-8.

16. Possover MRK, Chiantera V. The "neurologic hypothesis": a new concept in the pathogenesis of the endometriosis? Gynecol Surg. 2005;2:107-11.

17. Siquara de Sousa AC, Capek S, Howe BM, Jentoft ME, Amrami KK, Spinner RJ. Magnetic resonance imaging evidence for perineural spread of endometriosis to the lumbosacral plexus: report of 2 cases. Neurosurg Focus. 2015;39:E15

18. Sasson IE, Taylor HS. Stem cells and the pathogenesis of endometriosis. Ann N Y Acad Sci. 2008:1127:106-15.

19. Benardete-Harari DN, Muñoz-de Cote Frade JM, Hidalgo-Carrera JA, Felgueres-Hermida A, Meraz-Ávila D. [Primary umbilical endometriosis (Villar's nodule): case report.] Rev Med Inst Mex Seguro Soc. 2018;56:203-6.

20. Genoveses G, Veraldi S, Passoni E, Nazzaro G. Ultrasonographic findings in primary umbilical endometriosis. An Bras Dermatol. 2018:93:297-8.

21. Van Den Nouland D, Kaur M. Primary umbilical endometriosis: a case report. Facts Views Vis Obgyn. 2017;9:115-9. 